\title{
Use of Honey in Management of Diabetic Foot Infection: Patient's Satisfaction and Outcome
}

\author{
Alexander Kosternoy ${ }^{1}$, Emad K. Bayumi ${ }^{2}$ \\ ${ }^{1}$ Head of surgical gastroentrology in Medical Academy named after S.I. Gergivesky of Crimea Federal University, Crimea, Russia \\ ${ }^{2}$ Researcher PhD General Surgery, Medical Academy Named after S.I. Georgiesky of Crimea Federal University, Crimea, Russia
}

Email address:

Emadsurg666@hotmail.com (E. K. Bayumi)

\section{To cite this article:}

Alexander Kosternoy, Emad K. Bayumi. Use of Honey in Management of Diabetic Foot Infection: Patient's Satisfaction and Outcome. Journal of Surgery. Special Issue: Postoperative Pain Syndrome. Vol. 3, No. 2-1, 2015, pp. 42-47. doi: 10.11648/j.js.s.2015030201.19

\begin{abstract}
Introduction: diabetic foot is a major economic problem, and its management has not always been performed in a most cost effective way. This study on diabetic foot infection aimed at comparison of the effect of bee honey with another concentrated carbohydrate solution like glycerin and with a group using betadine and saline. Patients, Materials and Methods: The patients were divided into three groups; Group A: dressing with bee honey, Group B: dressing with glycerin magnesia and Group C: represented the control group dressed with Betadine and Saline. Results: We observed that the tested materials had positive effects on diabetic foot infections but honey surpassed all by reducing the debridement times and the load of infecting organisms. Conclusion: Local wound care plays a good role when topically applied to treat diabetic foot wounds. Honey seems effective in combating infection and helps wound healing.
\end{abstract}

Keywords: Diabetic Foot, Honey, Patient's Satisfaction

\section{Introduction}

Diabetic foot refers to any pathology that affects the foot resulting from diabetes or its long-term complications. The diabetic foot is a major economic problem, and its management has not always been performed in a most cost effective way [1]. Hydrocolloid gel applied to the wound and covered by a semi-occlusive dressing can be used. Materials composed of calcium alginate allow absorption of wound exudates. Saline strength betadine dampened gauze packed in a wound and allowed to dry is a simple cost effective method [2].

Honey as an adjuvant for acceleration of wound healing is widely accepted in Falk medicine and the use of wound salves containing honey was mentioned in Egyptian papyri dating from before $2000 \mathrm{BC}$ [3]. Honey was alleged to possess a wide variety of activities due to its physical properties, antibacterial power, epithelial regeneration, antioxidants it contains, and lastly the power to release cytokines and interleukines from their stores [4]. Application of honey to severely infected cutaneous wounds is capable of clearing infection from the wound and improving tissue healing owing to physicochemical properties, stimulation of the immune response and antibacterial actions [5].
This study on diabetic foot infection aimed at comparison of the effect of bee honey with another concentrated carbohydrate solution like glycerin and with a group using betadine and saline .

\section{Patients, Materials and Methods}

\subsection{Patients}

The present study has been conducted on forty-five diabetic patients presented with lower extremity purulent problems in our department during the period from January 2013 to August 2014. All patients were evaluated clinically, laboratory and radiologically to assess their present status and to plan for the future management aiming at decreasing morbidity and mortality with decreasing patient disability by establishing a protocol of management and future rehabilitation.

The patients were divided into three groups; with 15 patients in each:

Group A: dressing with bee honey

Group B: dressing with glycerin magnesia

Group C: represented the control group dressed with Betadine and Saline. 


\subsection{Materials and Methods}

All patient were evaluated on admission for the risk factors as age, smoking, onset and duration of diabetics, hypertension, coronary artery disease (CAD) and renal impairment. Patients presented with diabetic foot problems with acute or chronic peripheral ischaemia were excluded from the study.

\subsubsection{Management Program and Guidelines}

All patients were subjected to a protocol of management for control of hyperglycemia and infection and local wound care and dressing

\subsubsection{Control of Infection}

Materials used for microbiological evaluation of the infection were curettage of the base of the ulcer after debridement, aspiration of the abscess material and sent to the Microbiology Unit of Al Hayat Hospital, Jeddah in a special transport "Stewart's" medium. All specimens were examined as gram-stained smears and cultured aerobically on blood agar and McConkey agar plates and anaerobically on blood agar and incubator for 24 hours.

The isolated microorganisms were identified and the in vitro antimicrobial susceptibility of the bacteria isolated was determined by the disk diffusion. Empirical parentral broadspectrum antibiotics against gram-positive, gram-negative and anaerobic organisms were used initially. Modification to a more specific antibiotic when initial culture and sensitivity results became available was mandatory. Infection was considered adequately controlled when cellulitis, lymphagitis and edeme had resolved and wounds were free from purulence

\subsubsection{Debridement and Drainage}

Plain radiographic films of foot were obtained to detect the presence of foreign bodies, soft tissue gas, neuropathic foot deformities or fractures and bone changes suggestive of osteomylitis. Patients with undrained pus or extensive necrosis underwent incision and drainage, debridement or open minor amputation as needed. All amputations, extensive debridement or procedures in sensate patients were performed in the operating room. Densely neuropathic patients with limited necrosis or abscess underwent incision and drainage or debridement at the bed- side. Incisions were placed in such a manner as to promote dependent drainage.

The concept of amputation as a drainage procedure was of particular importance. When a single toe was necrotic or gangrenous and a localized abscess was present at its base or at the web space, adequate drainage could be accomplished only by removal of the toe and generous drainage of the web.

\subsubsection{Dressing}

Once infections had been adequately drained, attentive post-operative care was important in minimizing further tissue loss and achieving limb salvage. All wounds were examined daily and follow-up bedside sharp debridement was performed as needed to remove residual infected or necrotic tissue. The condition of the wound determined the frequency of dressing i.e. in discharging wounds the dressing was done 2-3 times per day, while in clean or granulating wounds; it was done once/day or even every other day in order not to disturb the granulation tissue.

\subsubsection{Follow-Up}

Status of the foot lesion on discharge from the hospital determines post-hospitalization care. In general, those patients discharged from the hospital with partially healed wounds were continued on oral antibiotic until healing was complete.

All patients discharged were monitored frequently (approximately once weekly) until full healing Occurred. Additional visits every month continued for 6 months. Foot examination for the previous lesion or any new lesion was thoroughly searched for.

\subsubsection{Definitions}

\section{(i). Partially Clean Wound}

The authors used the status of stoppage of pus discharge but with no attempt at granulation tissue formation to describe the wound as partially clean.

\section{(ii). Clean Red Wound}

Proper attempt at granulation tissue formation was used to describe the wound as red clean.

\section{(iii). Complete Healing}

By complete healing, the authors meant full epithelial coverage.

\section{Results}

There were no significant difference in the patients of the three groups as regard to their demographic data including age, sex, body mass index (BMI), duration of diabetes and smoking as seen in table 1 .

Table 1. showing the demographic data for patients of both groups.

\begin{tabular}{|c|c|c|c|c|c|c|c|}
\hline \multirow{2}{*}{ Group } & \multirow{2}{*}{$\begin{array}{l}\text { Age } \\
\text { Mean } \pm \text { SD }\end{array}$} & \multicolumn{2}{|l|}{ Sex } & \multirow{2}{*}{$\begin{array}{l}\text { BMI } \\
\text { Mean } \pm \text { SD }\end{array}$} & \multirow{2}{*}{$\begin{array}{l}\text { Diabetes } \\
\text { Mean } \pm \text { SD }\end{array}$} & \multicolumn{2}{|c|}{ Smoking } \\
\hline & & Male & Female & & & Yes & No \\
\hline A & $54.53 \pm 8.57$ & 6 & 9 & $26.8 \pm 2.68$ & $9.46 \pm 5.74$ & 4 & 11 \\
\hline B & $53.33 \pm 4.83$ & 7 & 8 & $25.66 \pm 2.74$ & $12.3 \pm 4.67$ & 5 & 10 \\
\hline $\mathrm{C}$ & $53.20 \pm 6.75$ & 8 & 7 & $25 \pm 2.57$ & $10.8 \pm 5.30$ & 6 & 9 \\
\hline
\end{tabular}

The clinical presentations of our patients were foot abscess, pus-discharging wound, dorsal foot ulcer, plantar ulcer with and without bone exposure, osteomyelitis and gangrene and the detailed distribution was shown in table 2. $\mathrm{P}$ value was $>$ 0.05 i.e. no significant difference between the three groups as regards the types of foot lesions. 
Table 2. showing the clinical presentation of patients in both groups.

\begin{tabular}{|c|c|c|c|c|c|c|c|c|}
\hline \multirow{2}{*}{ Presentation } & \multicolumn{2}{|l|}{$\mathbf{A}$} & \multicolumn{2}{|l|}{ B } & \multicolumn{2}{|l|}{ C } & \multicolumn{2}{|c|}{ Total } \\
\hline & No & $\%$ & No & $\%$ & No & $\%$ & No & $\%$ \\
\hline Abscess & 3 & 6.66 & 1 & 2.22 & 3 & 6.66 & 7 & 15.55 \\
\hline $\begin{array}{l}\text { discharging } \\
\text { wound, }\end{array}$ & 2 & 4.44 & 2 & 4.44 & 1 & 2.22 & 5 & 11.11 \\
\hline $\begin{array}{l}\text { Dorsal ulcer } \\
\text { Plantar ulcer: }\end{array}$ & 2 & 4.44 & 1 & 2.22 & 2 & 4.44 & 5 & 11.11 \\
\hline $\begin{array}{l}\text { With exposed } \\
\text { bone }\end{array}$ & 2 & 4.44 & 3 & 6.66 & 3 & 6.66 & 9 & 20 \\
\hline $\begin{array}{l}\text { Without } \\
\text { exposed bone }\end{array}$ & 5 & 11.11 & 5 & 11.11 & 3 & 6.66 & 12 & 26.66 \\
\hline osteomyelitis & 3 & 6.66 & 5 & 11.11 & 4 & 8.88 & 12 & 26.66 \\
\hline gangrene. & 1 & 2.22 & 3 & 6.66 & 3 & 6.66 & 7 & 15.55 \\
\hline
\end{tabular}

The microorganisms isolated most frequently were proteus mirabilis $(33.3 \%)$, Escherichia coli $(22.2 \%)$, pseudomonas aeruginosa $(20 \%)$ and klebsiella pneumonia (17.8\%) while staph. Aureus (8.9\%). Table 3 illustrated the microorganisms isolated from diabetic foot infections of 42 patients.

Table 3. Showed the isolated micro-organisms from diabetic foot wounds in patients of the three groups.

\begin{tabular}{lllllll}
\hline \multirow{2}{*}{ Microorganisms } & \multicolumn{2}{l}{ Group A } & \multicolumn{2}{l}{ Group B } & \multicolumn{2}{c}{ Group C } \\
\cline { 2 - 8 } & No. & \%* & No. & \%* & No. & \%* \\
\hline Gram-positive aerobes & 4 & & & & & \\
Staph. aureus & 1 & 2.38 & - & - & 1 & 2.38 \\
Coagulase -ve staph. & - & - & - & - & 2 & 4.76 \\
Strept. faecalis & - & - & 1 & 2.38 & - & \\
Gram-negative aerobes & 48 & & & & & \\
Escherichia coli & 2 & 4.76 & 5 & 11.9 & 3 & 7.14 \\
Klebsiella pneumonia & 2 & 4.76 & 3 & 7.14 & 3 & 7.14 \\
& 7 & 16.6 & 4 & 9.52 & 4 & 9.52 \\
Proteus mirabilis & 4 & 9.52 & 3 & 7.14 & 2 & 4.76 \\
Pseudomonas aeroginosa & 2 & 4.76 & 2 & 4.76 & 1 & 2.38 \\
Enterobacter spp. & 1 & 2.38 & - & & - & \\
Acinobacter & 5 & & & & & \\
Anaerobes & 2 & 4.76 & 2 & 4.76 & 1 & 2.38 \\
P. melaninogenicus & & & & &
\end{tabular}

of stoppage of pus discharge in $12(80 \%)$ cases from the next post-operative day and as long as honey is being applied in a fully sterile way under medical supervision; in 9 (60\%) cases of them, the wounds were free of infection and completely healed after 6 weeks of application of honey while, the other 3 cases showed healthy granulation tissue and submitted for coverage with theirsh graft. In the remaining 3 cases of this group A; 2 cases were submitted for heel reconstruction after eradication of infection, and the 3 rd case was complicated by repeated infection due to incomplete debridement or progressive tissue death and negligent dressings away from medical supervision.

In group B, treated with glycerin magnesium, it was found that $11(73.3 \%)$ cases became clear of infection by the end of the 3 rd week; $7(46.6 \%)$ cases of them were completely healed after 6 weeks and 4 cases $(26.6 \%)$ showed healthy granulation tissue and were submitted for coverage with theirsh graft and secondary closure of the stump after amputation of the gangrenous toe. In the other 4 cases; 3 of them were submitted for heel reconstruction of the heel defect, and one case was complicated by repeated infection of the amputation stump.

In group $\mathrm{C}$, treated with Betadine and Saline, it was found that, repeated bed side debridement was needed every 2-3 days to help removal of the necrotic tissue. The outcome after 6 weeks was the complete healing of only $6(40 \%)$ cases, with $4(26.7 \%)$ cases showing healthy granulation tissue and were submitted for theirsh graft, and secondary closure of the stump after amputation of the gangrenous toe. The fate of the other 5 cases was as follows:

- 2 cases were submitted for heel reconstruction

- 1 case readmitted with severe infection and had undergone below knee amputation

- 2 cases disappeared from follow-up

Wounds showed marked clinical improvement in the form

Table 4. clinical improvement in relation to time.

\begin{tabular}{|c|c|c|c|c|c|c|c|c|}
\hline $\mathbf{G}$ & \multicolumn{4}{|l|}{6 week } & \multicolumn{4}{|c|}{9 weeks } \\
\hline \multirow{2}{*}{ A } & 9 & 3 & 3 & \multirow{6}{*}{ NS } & 2 & 2 & 1 & \multirow{6}{*}{ NS } \\
\hline & $60 \%$ & $20 \%$ & $20 \%$ & & $33.3 \%$ & $33.3 \%$ & $16.7 \%$ & \\
\hline \multirow{2}{*}{ B } & 7 & 4 & 4 & & 3 & 3 & 2 & \\
\hline & $46.7 \%$ & $26.7 \%$ & $26.7 \%$ & & $37.5 \%$ & $37.5 \%$ & $33.3 \%$ & \\
\hline \multirow{2}{*}{$\mathrm{C}$} & 6 & 4 & 5 & & 2 & 2 & 2 & \\
\hline & $40 \%$ & $26.7 \%$ & $33.3 \%$ & & $33.3 \%$ & $33.3 \%$ & $33.3 \%$ & \\
\hline
\end{tabular}

\section{Discussion}

Many studies link non-healing wounds in diabetic patients with poor glucose control [6]. Increasing fasting plasma glucose levels and duration of diabetes were both associated with an increased risk of lower extremity amputation [7]. Early debridement is essential in controlling infection as delay may result in extension of tissue destruction and potentially in limb loss. Most incisions can be placed so that the weight-bearing surface of the foot is left intact, and if the blood supply is adequate, they will heal by second intention. The concept of minor amputation as a drainage procedure is of particular importance [8].

In this study, debridement was done in $73.3 \%$ for patients in group A, $73.3 \%$ in group B, and $60 \%$ for group C. It was repeated when indicated. Debridement is the removal of necrotic and infected materials from the wound and is considered the first and the most important therapeutic step leading to wound closure and a decrease in the possibility of limb amputation in patients with diabetic foot infection [9] Debridement seems to decrease bacterial counts and 
stimulates production of local growth factors. It also reduces pressure, evaluates the wound bed, and facilitates wound drainage [ 10 ].

Microbiologically, diabetic foot infections are generally polymicrobial and among the most frequently isolated microorganisms from the lesions in this study were Proteus mirabilis and Pseudomonas aeroginosa. The incidence of staph. aureus in our cases is lower than that reported by others [11]. This difference can be explained by the difference in severity of infections between the two studies, as most mild infections are caused by aerobic gram-positive cocci such as Staph aureus and Streptococci while deeper, limb threatening infections are polymicrobial and caused by gram-positive cocci, gram-negative bacilli (e.g. Escherichia coli, Klebsiella and Proteus species) and anaerobes (e.g. Bacteroides species) as found in our study.

Daily foot care and dressing was an important point in the management. It was done 2-3 times/ day during early phases of infection control according to presence or absence of infection and/ or necrotic tissue; wound state of discharge and formation of granulation tissue [12]. Eaglastein and Falanga found that daily care of the diabetic wound is not less important than vascular bypass or amputation [13].

In group A treated with honey, it was found that the amount of honey required on the wound is related to the amount of fluid exuding from the wound diluting it, the frequency of dressing changes required will depend on how rapidly the honey is being diluted by exudates and to achieve best results, the honey should be applied to an absorbent dressing prior to application to hold it in place. Thus, for moderately to heavily exuding wounds, dressing was done 23 times per day.

The clearing of infection seen when honey is applied to a wound may reflect more than just antibacterial properties. Researchers showed that the proliferation of peripheral blood B- lymphocytes and T-lymphocytes in cell culture is stimulated by honey at different concentrations [2,14]. Honey also stimulates monocytes in cell culture to release cytokines, tumor necrosis factor (TNF), interleukin (IL)-1 and IL-6, which activate the immune response to infection [15]. Use of honey for dressing is gaining popularity in the management of chronic wounds as it provides a moist wound environment that promotes autolytic debridement of necrotic tissue and may be a useful adjunct to serial sharp debridement [16].

Antimicrobial activity of honey has been attributed to hydrogen peroxide and phenolic compounds, although lethality of and inhibition by these and other components against microorganisms vary greatly, depending on the floral source of nectar [ 17].The ability of honey to kill microorganisms has been attributed to its high content of tetracycline derivatives, peroxidases, fatty acids, phenols, ascorbic acids and amylases [17,18]. Honey is effective in preventing the growth of Pseudomonas, even if the honey is diluted more than 10-fold by exudation from wounds. Natural and diluted honey (50\%) in broth and solid cultures inhibited Bacteroides isolated from dental infections [ 17,19]

The failure to take into account the large variance in antibacterial potency of different honeys may contribute, in part, to the large discrepancy in results reported between hospitals using honey in similar ways. Some have reported rapid clearance of infection in a range of different types of wounds, with all wounds being sterile in 2 weeks [20] and others have reported bacteria still present in wounds after 3 weeks [21].

A much more interesting effect of honey is its ability to enhance autodebridement by absorbing edematous fluid around the ulcer margins and promotes granulation tissue formation and epithelialization [22]. Honey was said to have chemotactic for macrophages and promotes macrophage activation by enhancing the release of both TNF-a and interleukin-1b from monocytes. Macrophages serve to limit tissue damage, also remove damaged connective tissue and cell debris, kill pathogens, initiate new vascularization, and stimulate fibroblast [17,23].

Povidone iodine (Betadine) is a bactericidal topical agent which can destroy surface bacteria although it can be cytotoxic to the granulation tissue and it has no debriding or healing prompting action.

Application of povidone iodine proves to be effective at reducing bacteria numbers and decreasing wound infections and at the same time impairs collagen synthesis, has a toxic effect on fibroblasts and keratinocytes, and impairs epithelial cell migration, therefore potentially having a detrimental effect on the healing process [24 ]. Iodine dressings must be used with care in patients with thyroid diseases, in pregnant or breastfeeding women or in newborn babies and up to the age of six months [25]. Glycerin-based materials showed statistically significant reduction of the mean infection scores in patients when used as wound dressings [26]. It has been shown that glycerin at high concentration will be cytotoxic to all cells that have been tested if they are exposed long enough [27].

Contrary, honey antimicrobial action explains the external and internal uses of honey. Honey has been used to treat adult and neonatal postoperative infection, burns, necrotizing fasciitis, infected and nonhealing wounds and ulcers, boils, pilonidal sinus, venous ulcers, and diabetic foot ulcers [28].

Long-term use of povidone iodine has been loosely associated with mild hyperthyroidism and long-term use is not recommended for patients with impaired thyroid function. It has been suggested that iodine has a negative impact on cells involved in the wound healing process and because of this its safety and efficacy have been questioned [24]. In contrast, the honey-based product showed excellent cytocompatibility with tissue cell cultures [29] and for long term use as in the management of chronic foot ulcers proved to be efficacious, cost-effective, and acceptable by both clinicians and patients [30].

No significant differences in the outcome were detected between the 3 groups. However, because of the small size of the study, this should be interpreted as being an insufficient evidence of topical effect of honey, rather than being an evidence of its little effect.

Future trials of dressing with bee honey for diabetic foot 
ulcers, therefore need to be done on larger numbers of patients. In addition the role of co-interventions, such as wound debridment and weight bearing measures should be explored.

\section{Conclusion}

Foot complications in diabetics are one of the most serious and costly complications of diabetes mellitus. Amputation of (or part of) a lower extremity is usually preceded by a foot ulcer. The basic principles of prevention and treatment depend upon local circumstances. Local wound care plays a good role when topically applied to treat diabetic foot wounds. Honey seems effective in combating infection and helps wound healing

\section{References}

[1] Lee CM, Chang CC, Pan MY, Chang CF, Chen MY. Insufficient early detection of peripheral neurovasculopathy and associated factors in rural diabetes residents of Taiwan: a cross-sectional study. BMC Endocr Disord. 2014 Nov 24;14:89. doi: 10.1186/1472-6823-14-89.

[2] Seabrook GR, Towne JB: Management of foot lesions in the diabetic patient. In: Ruther- ford vascular surgery. 5th Ed WB Saunders, 2000; Ch 76:1093-1102.

[3] Al-Benna S, Al-Ajam Y and Steinstraesser L. The evidence base for the wound healing properties of honey. Burn, 2009; 35 (1): S21-S22.

[4] Saber A. Effect of honey versus intergel in intraperitoneal adhesion prevention and colonic anastomotic healing: A randomized controlled study in rats. International Journal of Surgery 8 (2010) 121-127

[5] Saber A, Shekidef MH, El-Daharawy MH. Fecal Peritonitis in Rats. J. Adv. Vet. Res. 2011; 1(1): 8-12.

[6] Greenhalgh DG. Wound healing and diabetes mellitus. Clin Plast Surg. 2003 Jan;30(1):37-45

[7] Tsourdi E1, Barthel A, Rietzsch H, Reichel A, Bornstein SR. Current aspects in the pathophysiology and treatment of chronic wounds in diabetes mellitus. Biomed Res Int. 2013;2013:385641. doi: 10.1155/2013/385641.

[8] Mandracchia VJ, Yoho RM, Buddecke DE, et al: The diabetic foot: Treatment strategies. Hospita Medicine 1999; 35(1): 2733

[9] Tallis A, Motley TA, Wunderlich RP, Dickerson JE, Waycaster C, Slade HB. Clinical and economic assessment of diabetic foot ulcer debridement with collagenase: results of a randomized controlled study. Clin Ther.2013;35:1805-1820.

[10] DiPreta JA. Outpatient assessment and management of the diabetic foot. Med Clin North Am. 2014;98:353-373

[11] Goldstein ES, Citron DM, Nesbit CA: Diabetic foot infections. Bacteriology and activity of 10 oral antimicrobial agents against bacteria isolated from consecutive cases. Diabetes Care 1996; 19:638-641.
[12] Mousley M. Diabetes and its effect on wound healing and patient care. Nurs Times. 2003 Oct 21-27;99(42):70, 73-4.

[13] Eaglestein WH, Falanga V: Chronic wounds. Surgical Clinics of North America 1997; 77( 3): 144-162

[14] Abuharfeil N, Al-Oran R, Abo-Shehada M. The effect of bee honey on the proliferative activity of human B- and Tlymphocytes and the activity of phagocytes. Food Agric. Immuno 1999; 11:169-77.

[15] Molan PC, Tonks A, Cooper RA, Price AJ, Jones KP: Stimulation of tnf-alpha release in monocytes by honey. Cytokine 2001; 14(4):240-2.

[16] Pieper B. Honey based dressings and wound care: an option for care in the United States. JWOCN. 2009. 36(1); 60-66.

[17] Saber A. Effect of Intergel versus Honey in Intraperitoneal Adhesion Prevention and Colonic Anastomotic Healing: A Comparative Experimental Study in Rats. A thesis Submitted For Partial Fulfillment of M.D Degree In General Surgery. Faculty of Medicine, Suez-Canal University, Egypt; 2005.

[18] Nzeako B C1\& Hamdi J. Antimicrobial potential of honey on some microbial isolates. SQU J Sc Res (2000), 2: 75-79

[19] Al-Waili NS. Investigating the Antimicrobial Activity of Natural Honey and Its Effects on the Pathogenic Bacterial Infections of Surgical Wounds and Conjunctiva. J Med Food (2004), 7 (2): 210-222

[20] Hariss S: Honey for the treatment of superficial wounds: a case report and review. Pr mary Intention 1994; 2(4): 18-23

[21] Subrahmanyam M: A prospective randomised clinical and histological study of superficial burn wound healing with honey and silversulfadiazine. Burns 1998; 24 (2): 157-61

[22] Shukrimi A, Sulaiman AR , Halim AY, Azril A. A Comparative Study Between Honey and Povidone Iodine as Dressing Solution for Wagner Type II Diabetic Foot Ulcers. Med J Malaysia 2008; 63 ( 1): 44-46

[23] Tonks J, Cooper RA,. Jones KP et al. Honey stimulates inflammatory cytokine production from monocytes. Cytokine (2003),21: 242-247

[24] Angel DE, Morey P, Storer JG and Mwipatayi BP. The great debate over iodine in wound care continues: a review of the literature. Wound Practice and Research. 2008; 16(1): 6-21

[25] Sibbald RG, Leaoer DJ, Queen D. Iodine Made Easy. Wounds International 2011; 2(2): S1-S6.

[26] Blumenstein I, Borger D, Loitsch S, Bott C, Tessmer A, Hartmann F, Stein J. A glycerin hydrogel- based wound dressing prevents peristomal infections after percutaneous endoscopicgastrostomy (PEG): a prospective, randomized study. Nutr Clin Pract. 2012 Jun;27(3):422-5.

[27] Stout EI and McKessor A. Glycerin-Based Hydrogel for Infection Control. Adv Wound Care (New Rochelle). 2012 Feb; 1(1): 48-51.

[28] Al-Waili NS1, Salom K, Butler G, Al Ghamdi AA.. Honey and microbial infections: a review supporting the use of honey for microbial control. J Medicinal Food. 2011, 14(10): 10791096 
[29] Alam F, Islam MA, Gan SH1, Khalil MI. Honey: a potential therapeutic agent for managing diabetic wounds. Evid Based Complement Alternat Med. 2014;2014:169130. doi: 10.1155/2014/169130. Epub 2014 Oct 15.

[30] Mohamed H, Salma MA, Al Lenjawi B, Abdi S, Gouda Z,
Barakat N, Elmahdi H, Abraham S2, Hamza AH, Al Khozaei D, Al Majid S, Al Majid H,Abdini J, Al Jaber M, Al Masseh F, Al Ali AA. The efficacy and safety of natural honey on the healing of foot ulcers: a case series. Wounds. 2015 Apr;27(4):103-14. 